\title{
Serum glutamate dehydrogenase is not a reliable marker of liver cell necrosis in alcoholics
}

\author{
WJ JENKINS, SB ROSALKI, Y FOO, PJ SCHEUER, E NEMESANSZKY,* \\ S SHERLOCK
}

From the Departments of Medicine, Chemical Pathology and Histopathology, Royal Free Hospital and School of Medicine, Pond Street, London NW3 2QG

SUMMARY Serum glutamate dehydrogenase (EC 1.4.1.3.) activity was measured in 73 hospital patients who had a history of chronic alcohol abuse and who all had a liver biopsy performed.

High levels of serum GDH activity occurred in those patients with recent excess alcohol consumption independently of the underlying liver histology, and did not discriminate between those patients with and those without alcoholic hepatitis.

Since alcoholic hepatitis is thought to be a precursor of cirrhosis, a convenient and reliable marker of liver cell necrosis would be extremely useful in following the progress of liver disease in alcoholic patients. Repeated liver biopsies are impractical for monitoring purposes, and raised activities of the so-called hepatic enzymes commonly measured in serum are found in all histological stages of alcoholic liver disease from steatosis to cirrhosis. ${ }^{1}$ Conversely in alcoholic hepatitis the serum transaminase activities may be only moderately raised or even normal. ${ }^{2}$ Furthermore, the transaminases are not specific to the liver, and raised serum activities may reflect damage to other organs. Gamma-glutamyl transpeptidase (EC 2.3.2.2.) ( $\gamma \mathrm{GT})$ has been suggested as a useful marker of alcoholic liver disease, ${ }^{3}$ but the correlation between raised serum $\gamma \mathrm{GT}$ activities and liver cell necrosis is poor, ${ }^{4}$ and increases due to other hepatic causes are common.

The level of glutamate dehydrogenase (GDH) in serum might be expected to provide a more reliable index of liver damage in alcoholics, since its activity in the liver is very much higher than in other organs. ${ }^{5}$ Also, it is concentrated in the centrilobular zones of the liver, where alcohol exerts its greatest toxic effects, ${ }^{6}$ and within the hepatocytes it is found exclusively in mitochondria, which are thought to be damaged early in the course of alcoholic liver disease. ${ }^{7}$ In a study of 100 alcoholic patients, Van Waes and Lieber claimed that the serum activity

Accepted for publication 3 July 1981

* Present address: Postgraduate Medical School, 1st Department of Mericine, 1135 Budapest, Hungary. of GDH reliably reflects liver cell necrosis, and that a serum value two and a half times the normal value is indicative of alcoholic hepatitis. ${ }^{8}$ For these reasons it was suggested that the serum GDH activity should be estimated routinely in alcoholics. However, the possibility that recent alcohol consumption might increase serum activities of GDH independent of histological change was not investigated. GDH activity is considerably raised in liver biopsies from recently drinking patients with alcoholic steatosis, ${ }^{9}$ and high activities of the enzyme in serum may at least partly reflect this increase in hepatic activity.

We have studied the effect of recent heavy consumption of alcohol on the activity of GDH in both serum and liver in unselected alcoholic patients undergoing diagnostic liver biopsy, and tested the usefulness of serum GDH measurement in discriminating between those with and those without alcoholic hepatitis.

\section{Patients and methods}

PATIENTS

Seventy-three inpatients ( 56 men, 17 women) were studied. They all had a history of alcohol abuse, and all had either symptoms, physical signs, or biochemical evidence of liver disease. Other possible causes of liver disease besides alcohol were excluded by the relevant investigations. The reasons for admission to hospital varied. Some patients were admitted for diagnostic liver biopsy, some for detoxification, and some had the clinical syndrome of overt alcoholic hepatitis. All had a percutaneous liver biopsy performed. Venous blood was sampled 
for serum enzyme analysis thirty minutes before the biopsy.

A detailed history of alcohol drinking was taken from each patient. The patients were divided arbitrarily into those who had consumed $>80 \mathrm{~g}$ of ethanol/day immediately before liver biopsy, designated the "recent alcohol excess" group, and those who had consumed $<80 \mathrm{~g}$ of ethanol/day in the preceding week, designated the "no recent alcohol excess" group. In practice many of the patients admitted specifically for liver biopsy had considerably reduced their alcohol intake before admission, and others, particularly those with alcoholic hepatitis, had been in hospital without alcohol for more than a week before liver biopsy was performed.

Twelve non-alcoholic patients admitted for liver biopsy for suspected liver disease, but who had normal serum liver function tests at the time, and whose liver biopsies were subsequently found to be normal, were used as controls in the study of GDH activities in the liver.

\section{HISTOLOGY}

Histology of the liver biopsies was interpreted independently without knowledge of the serum enzyme analyses. Sections were stained by standard methods and examined for the presence of fat, inflammation, fibrosis, necrosis and Mallory bodies. Eight patients had histologically normal livers; 38 had alcoholic steatosis; 19 had alcoholic hepatitis with, or without fat or cirrhosis; and eight had cirrhosis without evidence of alcoholic hepatitis.

ENZYME ASSAYS

Aspartate aminotransferase (AST), GDH and $\gamma \mathrm{GT}$ were assayed in serum by standard laboratory techniques. ${ }^{10-12}$ Serum AST was determined immediately, and the samples of serum were stored at $-20^{\circ} \mathrm{C}$ before GDH and $\gamma \mathrm{GT}$ were assayed. Most samples were examined within two weeks of collection, and all within two months. Stability studies confirmed that the activities of these enzymes were unaltered during storage for this period.

In 49 patients the amount of liver tissue obtained by biopsy exceeded that judged necessary for histological assessment. The remaining portions of these biopsies were disrupted in $0.25 \mathrm{~mol} / \mathrm{l}$ sucrose containing $3 \mathrm{mmol} / 1$ imidazole, $\mathrm{pH} 7 \cdot 4$, at $4^{\circ} \mathrm{C}$ in a glass Dounce homogeniser. GDH activity and protein content were assayed in the resulting homogenates.

The results were analysed statistically by the Wilcoxon rank sum test.

\section{Results}

Most of our alcoholic patients had raised activities of one or more of the serum enzymes assayed: 58 had raised serum AST; 59 had raised $\gamma \mathrm{GT}$; and 37 had raised GDH. Fig. 1 shows the individual values in patients with and without recent excessive

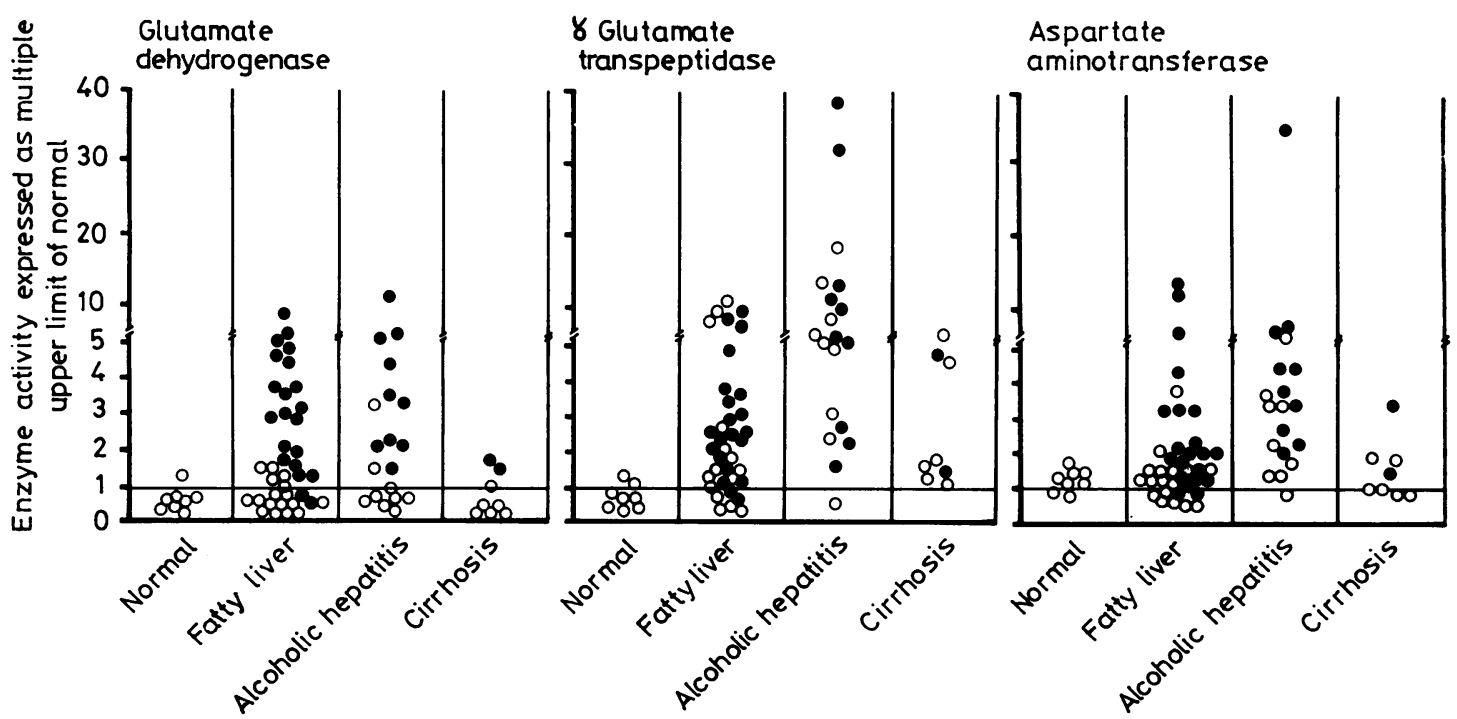

Fig. 1 Serum GDH, $\gamma$ GT and AST in alcoholic patients grouped by liver biopsy histology. ( $>80 \mathrm{~g}$ ethanol/day before biopsy; $\bigcirc<80 \mathrm{~g}$ ethanol/day before biopsy) 
consumption of alcohol grouped according to the histological diagnosis. Clearly the individual values of serum enzyme activities show a considerable overlap among the various histological groups, and serum GDH is no better than AST or $\gamma \mathrm{GT}$ in dis-

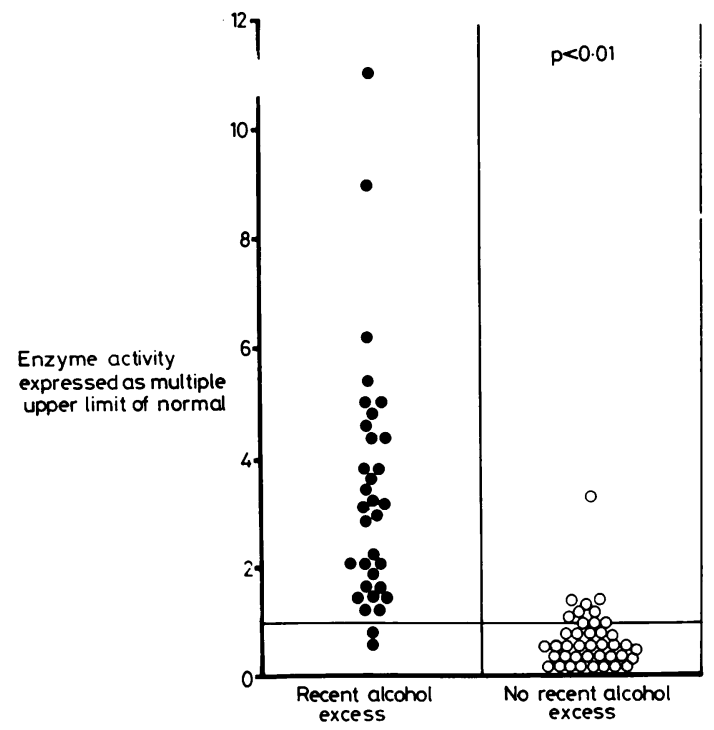

Fig. 2 Serum $G D H$ in alcoholic patients $(O>80 \mathrm{~g}$ ethanol/day before liver biopsy; $\bigcirc<80 \mathrm{~g}$ ethanol/day hefore biopsy)

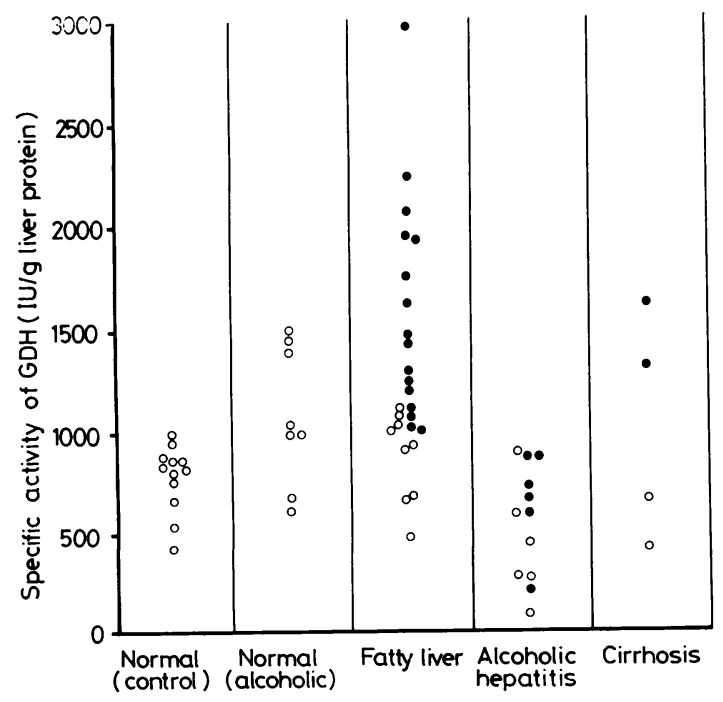

Fig. 3 Specific activity of GDH in liver biopsies from alcoholic patients grouped by histological diagnosis $(0<80 \mathrm{~g}$ ethanol/day before biopsy; $\bigcirc<80 \mathrm{~g}$ ethanol/day before biopsy). criminating between those with and those without alcoholic hepatitis. However, the serum GDH activity in those patients who were drinking heavily immediately before liver biopsy is significantly higher $(p<0.01)$ than in those who were not, irrespective of the underlying histological diagnosis (Fig. 2).

Fig. 3 shows the specific activities of GDH in 49 liver biopsies from alcoholic patients, and in the 12 control patients. The activities of GDH in the livers of those alcoholic patients, who had a history of recent alcohol excess and whose liver biopsies showed fatty change only, are significantly higher $(p<0.01)$ than in the normal controls. In contrast the hepatic activities of GDH are lower $(p<0.01)$ in those patients with alcoholic hepatitis presumably because of liver cell necrosis.

\section{Discussion}

Our results clearly contrast with those of a similar previous study of alcoholics, in which the activity of GDH in plasma was reported to be a reliable marker of liver cell injury. ${ }^{8}$ We found that the serum GDH activity was considerably raised in many of our alcoholic patients whose liver biopsies showed fatty change alone, whereas other patients with histologically proven and often severe alcoholic hepatitis had only slightly raised serum GDH activities. Thus, a serum GDH activity two and a half times the normal value does not discriminate between those alcoholic patients who had alcoholic hepatitis, and others who had not, as was previously claimed.

However, we have shown that recent heavy alcohol consumption increases the activity of GDH in both serum and liver. This is compatible with induction of the enzyme by alcohol, and limits the use of serum GDH measurement as an indicator of pathological change. Our patients were unselected, and so probably representative of those seen in clinical practice elsewhere. Since a high serum activity of GDH in alcoholics may result not only from liver cell necrosis, but also from recent alcohol excess, it is not a reliable marker of the former. In addition, its lower sensitivity compared with the other enzymes studied limits its value for identifying and monitoring the progress of alcoholic liver disease.

This work was supported by the Medical Council on Alcoholism. EN was a Wellcome Senior Research Fellow.

\section{References}

${ }^{1}$ Kallai L, Mahn A, Roder V, Zupanic V. Correlation between histological findings and serum transaminase values in chronic diseases of the liver. Acta Med Scand 
$1964 ; 175: 49-56$.

${ }^{2}$ Beckett AG, Livingstone AV, Hill KR. Acute alcoholic hepatitis. Br Med J 1961; ii:1113-9.

${ }^{3}$ Rosalki SB, Rau D. Serum $\gamma$-glutamyl transpeptidase activity in alcoholism. Clin Chim Acta 1972;39:41-7.

${ }^{+}$Wu A, Slavin G, Levi AJ. Elevated serum gammaglutamyl-transferase (transpeptidase) and histological liver damage in alcoholism. Am J Gastroenterol 1976; 65:318-23.

${ }^{5}$ Schmidt E, Schmidt FW. Methods and value of determination of glutamic acid dehydrogenase activity in the serum. A contribution to the importance of examination of enzyme relations in the serum. Klin Wochenschr 1962; 40:962-9.

${ }^{6}$ Guder WG, Habicht A, Kleissl J et al. The diagnostic significance of liver cell inhomogeneity: serum enzymes in patients with central liver necrosis and the distribution of glutamate dehydrogenase in normal liver. Z Klin Chem Klin Biochem 1975;4:70-5.

${ }^{7}$ Svoboda DJ, Manning RT. Chronic alcoholism with fatty metamorphosis of the liver. Mitochondrial alterations in hepatic cells. Am J Pathol 1964;44:645-52.

${ }^{8}$ Van Waes L, Lieber CS. Glutamate dehydrogenase: a reliable marker of liver cell necrosis in the alcoholic.
Br Med J 1977;ii:1508-10.

"Jenkins WJ, Peters TJ. Mitochondrial enzyme activities in liver biopsies from patients with alcoholic liver disease. Gut 1978;19:341-4.

${ }^{10} \mathrm{Karmen} \mathrm{A}$. A note on the spectrophotometric assay of glutamate-oxaloacetate transaminase in human blood serum. J Clin Invest 1955;34:131-3.

11 Jung K, Sokolowski A, Egger E. An optimised assay of human serum glutamate dehydrogenase activity. Enzı'me 1972/73;14:44-54.

12 Rosalki SB, co-ordinator. Association of Clinical Biochemist's Working Party Recommendations. Proposed methods for determination of some enzlmes in blood serum. Association of Clinical Biochemists News sheet supplement: February 1980.

${ }^{13}$ Lowry $\mathrm{OH}$, Rosebrough $\mathrm{NJ}$, Farr AL, Randall RJ. Protein measurement with the Folin phenol reagent. $J$ Biol Ch'm 1951;193:265-75.

Requests for reprints to: Dr WJ Jenkins, Academic Department of Medicine, The Royal Free Hospital, Pond Street, Hampstead, London NW3 2QG, England. 